Juan M. Pérez, Jesús Ma. Rincón, Maximina Romero Effect of moulding pressure on microstructure and technological properties of porcelain stoneware. Ceramics International Volume 38, Issue 1, January 2012, Pages 317-32; doi:10.1016/j.ceramint.2011.07.009

\title{
Effect of moulding pressure on microstructure and technological properties of porcelain stoneware
}

Juan M. Pérez, Jesús Ma. Rincón, Maximina Romero

Group of Glassy and Ceramic Materials, Instituto de Ciencias de la Construcción Eduardo Torroja, CSIC, C/Serrano Galvache 4, 28033 Madrid, Spain

\begin{abstract}
The properties of green and fired porcelain stoneware bodies have been studied in samples moulded at different pressures $(10,20,30$ and $40 \mathrm{MPa})$. In green tiles, higher differences in properties have been found at lower moulding pressure. After the fast-firing process, the tiles have been tested to obtain the technological properties such us lineal shrinkage, water absorption, porosity and bending strength. Results show that higher moulding pressures (30 and $40 \mathrm{MPa}$ ) give rise to tiles with similar technological properties. The amount of mullite and quartz remains constant in all pieces after firing process. SEM observations show that mullite crystals are longer as moulding pressure increases, that means that initial moulding pressure has a marked effect on mullite development, which is the main responsible of final properties.
\end{abstract}

Keywords D. Mullite; Moulding pressure; Microstructure; Porcelain stoneware

\section{Introduction}

The great development of porcelain stoneware tile was in the 80 s as a very compact vitrified product with high technical performances. Porcelain tiles are made from clay, fluxing agent and filler. Usually the clay is kaolinite, the fluxing agent is feldspar and the filler is quartz. Firing bodies containing these three components result in a grain and bond microstructure consisting of coarse quartz grains held together by a finer bond or matrix consisting of mullite crystals and a glassy phase [1].

Kaolinite is the precursor of mullite crystals and also it confers the plasticity to green paste. Mullite crystals are derived from the solid-state decomposition of the clay component [2], and are endowed with excellent mechanical, creep, thermal and chemical properties. It has been proved that mullite content affects the mechanical properties of porcelain stoneware. Thus, it was reported that the tile strength increases with increasing mullite content [3],[4] and [5], but also with the morphology of secondary mullite needles. Thus, in a recent paper Martín-Márquez et al. [6] have pointed out that bending strength is directly associated to the aspect ratio shown 
Juan M. Pérez, Jesús Ma. Rincón, Maximina Romero Effect of moulding pressure on microstructure and technological properties of porcelain stoneware. Ceramics International Volume 38, Issue 1, January 2012, Pages 317-32; doi:10.1016/j.ceramint.2011.07.009

by secondary mullite needles. An increase in the aspect ratio of crystals was observed to increase the bending strength, which reaches maximum values when mullite needles join together and give rise to clusters. The knowledge of mullite crystal formation on firing (amount and shape) is of great importance for enhancing the technological properties of porcelain stoneware tiles. Quartz effect on technological properties is still controversial. Some authors concluded that higher residual quartz content results in higher strength, but others reported that such a relationship is not very clear and the dependence even seems to be the opposite [7] and [8].

Porcelain stoneware tile is fabricated by a well established method, in which the dominant process for shaping green tiles is dry pressing (5-7\% moisture) at $40 \mathrm{MPa}$ using hydraulic presses. However, in literature green tiles are obtained by pressing the ceramic powder at pressures in the wider 30-55 MPa interval (Table 1). The use of high pressure devices requires high energy input, which contributes to the rising cost of porcelain stoneware tiles. After pressing, the green body should have sufficient mechanical strength to prevent damage during demoulding and transport to the oven processes. It is established that a mechanical strength of $1 \mathrm{~kg} / \mathrm{cm}^{2}$ is already sufficient to extract the piece from the die and convey it along and appropriate line [9]. This minimum value is overachieved in green bodies moulded at high pressures $\left(8 \mathrm{~kg} / \mathrm{cm}^{2}\right.$ for a traditionally pressed body at $\left.40 \mathrm{MPa}\right)$, and thus it will probably be reached in tiles at lower pressures. Abadir et al. [10] studied the effect of moulding pressures (35-55 MPa), and firing temperature and soaking time in porcelain tiles, but to authors' knowledge there are no studies employing lower pressures.

Table 1. Moulding pressure reported in literature for obtaining porcelain tiles.

\begin{tabular}{|c|c|c|c|c|c|}
\hline Moulding pressure & Dimension (mm) & $\begin{array}{c}\text { Firing process } \\
\text { Temperature } \\
\left({ }^{\circ} \mathrm{C}\right) \\
\end{array}$ & $\begin{array}{l}\text { Heating rate } \\
\left({ }^{\circ} \mathrm{C} / \mathrm{min}\right)\end{array}$ & $\begin{array}{l}\text { Soaking time } \\
(\min )\end{array}$ & $\begin{array}{c}\text { Reference } \\
\text { number }\end{array}$ \\
\hline $35,40,45$ & $10 \times 10 \times 70$ & 1200,1210 & 80 & $10,15,20$ & {$[10]$} \\
\hline 50, $55 \mathrm{Mpa}$ & $50 \times 50 \times 20$ & 1220,1230 & & & \\
\hline Not specified & $8 \times 20 \times 60$ & $1200-1420$ & 150 & 30 & {$[15]$} \\
\hline $5 \mathrm{MT}$ & $100 \times 14 \times 5$ & $1150-1300$ & - & 120 & {$[16]$} \\
\hline $40 \mathrm{MPa}$ & $60 \times 20$ & 1210 & 45 & 8 & {$[17]$} \\
\hline $45 \mathrm{MPa}$ & $\begin{array}{c}80 \times 20 \times 7 \\
7 \mathrm{~mm} \text { diameter } \times 6 \\
\mathrm{~mm} \text { thickness disks }\end{array}$ & $1210-1260$ & $\begin{array}{c}25-500{ }^{\circ} \mathrm{C}: 70500- \\
\text { Max. Temp: } 25\end{array}$ & $10-120$ & [18] \\
\hline
\end{tabular}


Juan M. Pérez, Jesús Ma. Rincón, Maximina Romero Effect of moulding pressure on microstructure and technological properties of porcelain stoneware. Ceramics International Volume 38, Issue 1, January 2012, Pages 317-32; doi:10.1016/j.ceramint.2011.07.009

The aim of the present work is not changing the well established industrial process of ceramic tile manufacture but rather, to get a better understanding of the influence of moulding pressure on technological properties of porcelain stoneware tile. Microstructure study is focused on mullite crystals, specifically to their aspect ratio because it is one of the main responsible of technological properties behaviour. For this, it has been employed the same composition and the best firing temperature determined by Martín-Márquez et al. [11]. Data obtained in previous paper is used as reference.

\section{Experimental procedure}

A standard porcelain stoneware body for tile production was prepared by mixing $50 \%$ kaolinitic clay (EuroArce), 40\% feldspar (Rio Pirón) and 10\% quartz sand. Typically, sodium feldspar is used as fluxing agent in the industrial manufacture of porcelain stoneware tile[12], [13] and [14]. However, Dondi et al. [12] studied 15 raw-material mixtures, formulated on the basis of a standard composition (40\% kaolin, 10\% quartz and 50\% feldspar), using a wide range of components proportions (20-65\% kaolin, 0-35\% quartz and 30-70 wt\% feldspar). Theses authors concluded that the nature of the feldspar used (sodium or potassium) did not significantly affect the crystalline phases (quartz and mullite) distribution after fastfiring. On the other hand, potassium feldspar will lead to a liquid phase with less viscosity than that derived from sodium feldspar and thus, it will favour the growth of secondary mullite needles. For this reason, in the present study potassium feldspar has been chosen as fluxing agent instead of sodium feldspar.

Chemical and mineralogical compositions of all raw materials were given in a previous paper [11]. All the above materials were crushed, grounded and finally powdered to $<160 \mu \mathrm{m}$ prior to further use. A standard porcelain stoneware composition was prepared by mixing $50 \%$ kaolinitic clay, $40 \%$ feldspar and 10\% quartz. Batches (300 g each) were prepared by milling the constituents with distilled water (1:1) for $30 \mathrm{~min}$, in a planetary ball mill and using alumina balls as grinding media. The resulting slurry was oven-dried overnight at $110{ }^{\circ} \mathrm{C}$, powdered in a porcelain mortar and pestle, and sieved to pass -100 mesh $(150 \mu \mathrm{m})$. The resulting powder was moistened by spraying with distilled water (6 wt $\%$ ) and square tiles (30 g each) were uniaxially pressed $(50 \mathrm{~mm} \times 50 \mathrm{~mm} \times 10 \mathrm{~mm})$ at the different pressures of $10,20,30$ and $40 \mathrm{MPa}$ in a steel die. After drying in an oven at $110{ }^{\circ} \mathrm{C}$, experimental work has been divided into two parts. The former is the study of the green tiles properties, as absolute and bulk density, and bending strength. The latter is the study of the green bodies fired at $1280{ }^{\circ} \mathrm{C}$ with a fast firing process[16]. The sintering temperature $\left(1280^{\circ} \mathrm{C}\right)$ is higher than that typically employed in the 
Juan M. Pérez, Jesús Ma. Rincón, Maximina Romero Effect of moulding pressure on microstructure and technological properties of porcelain stoneware. Ceramics International Volume 38, Issue 1, January 2012, Pages 317-32; doi:10.1016/j.ceramint.2011.07.009

industrial practice $\left(1200-1220^{\circ} \mathrm{C}\right)$. However, the temperature of $1280{ }^{\circ} \mathrm{C}$ has been chosen on the basis of previous studies on the effect of firing temperature on sintering, microstructure and mechanical properties of the porcelain stoneware body composition under study. Moreover, the facilities available in the industrial process are not usually accessible in minor-scale investigation in research laboratories, and therefore, it is necessary longer firing conditions (temperature and time) to achieve the commercial technological properties (see Refs. [15], [16], [18] and [19] in Table 1).

Absolute density of green tiles has been determined on bulk samples (approximately $1 \mathrm{~g}$ ) employing a helium pycnometer (Multipycnometer, Quantachrome Instruments), which uses gas displacement to determine the volume of sample under test.

Bulk density was measured in a hygroscopic balance, weighting the sample in air and immersed in distillate water. To avoid the collapse of the sample specimen during the test, the samples were previously protected with a waterproof coating (commercial lack).

Bending strength, $\sigma_{\mathrm{f}}$, was measured according to UNE-EN 843-1 in an electronic universal tester (ME-401/01, Servosis) on 10 test pieces of $50 \mathrm{~mm} \times 10 \mathrm{~mm} \times 8 \mathrm{~mm}$ by a three point loading test with a span of $36 \mathrm{~mm}$ and a crosshead speed of $0.1 \mathrm{~mm} / \mathrm{min}$ for green pieces and $1 \mathrm{~mm} / \mathrm{min}$ for fired pieces.

The sintering behaviour of samples fast-fired at $1280{ }^{\circ} \mathrm{C}$ was evaluated by using the vitrification curves, which in this case present the variation in properties as a function of moulding pressure. These vitrification curves will allow establishing the optimum moulding pressure at which the open porosity reaches a minimum, which usually corresponds to higher values of mechanical strength. Linear shrinkage and water absorption, which are directly related with open porosity, are properties easy to measure and hence, are usually used to represent the vitrification curves.

The linear shrinkage, LS (\%), of fired samples has been determined by means of the following equation:

$$
\mathrm{LS}=\frac{L_{\mathrm{s}}-L_{\mathrm{c}}}{L_{\mathrm{S}}} \times 100
$$

where $L_{\mathrm{s}}$ and $L_{\mathrm{c}}$ are the length $(\mathrm{mm})$ of the green and fired specimens, respectively. The linear shrinkage values obtained from six specimens were averaged for each firing temperature.

The water absorption, bulk density and apparent porosity were measured according to ASTM C373-88, which involves drying the test specimens to constant mass $(D)$, boiling in distilled 
Juan M. Pérez, Jesús Ma. Rincón, Maximina Romero Effect of moulding pressure on microstructure and technological properties of porcelain stoneware. Ceramics International Volume 38, Issue 1, January 2012, Pages 317-32; doi:10.1016/j.ceramint.2011.07.009

water for $5 \mathrm{~h}$ and soak for additional $24 \mathrm{~h}$ at ambient temperature. After impregnation, the mass $(S)$ of each specimen while suspended in water and their saturated mass $(M)$ is determined. The test was carried out on four representative specimens.

Water absorption, WA (\%), expresses the relationship of the mass of water absorbed to the mass of the dry specimen as follows:

$$
\mathrm{WA}=\frac{M-D}{D} \times 100
$$

The bulk density, $B\left(\mathrm{~g} / \mathrm{cm}^{3}\right)$, is calculated as follows:

$$
B=\frac{D}{V}
$$

where $V\left(\mathrm{~cm}^{3}\right)$ is the exterior volume $(V=M-S)$.

The open porosity, $\varepsilon_{0}(\%)$, expresses the relationship of the volume of open pores to the exterior volume of the specimen and is calculated as follows:

$$
\varepsilon_{0}=\frac{M-D}{V} \times 100
$$

The total porosity of the sample, $\varepsilon_{\mathrm{T}}(\%)$ is determined by the following equation:

$$
\varepsilon_{\mathrm{T}}=\left(1-\frac{B}{\mathrm{AD}}\right) \times 100
$$

where $\mathrm{AD}\left(\mathrm{g} / \mathrm{cm}^{3}\right)$ is the absolute density of the sample, which was previously measured according to ASTM C329-88, the test method involves crush, ground and sieve the sample to pass -80 mesh $(177 \mu \mathrm{m})$. The measurements were carried out on $8-10 \mathrm{~g}$ of powder sample by using a pycnometer (50 $\mathrm{ml}$ capacity) consisting of a suitable bottle with a capillary tube stopper. All determinations have been made in duplicate.

The close porosity, $\varepsilon_{\mathrm{c}}(\%)$, is then calculated as follows:

$\varepsilon_{\mathrm{c}}=\varepsilon_{\mathrm{T}}-\varepsilon_{0}$

$\mathrm{X}$-ray diffraction (XRD, Philips X'PERT MPD) was performed using $\mathrm{Cu} \mathrm{K} \alpha$ radiation with $\mathrm{Ni}$-filtered operating at $30 \mathrm{~mA}$ and $50 \mathrm{kV}$. The scanning speed was set at $2 \theta / \mathrm{min}$ with a time per step of 0.02s. Phase identification was done from the International Centre for Diffraction Data (PDF), Mullite (15-0776) and Quartz (46-1045). Phase assemblages and microstructure of fired specimens was examined by scanning electron microscopy (SEM) (JSM 6500F, JEOL) using an acceleration voltage of $20 \mathrm{kV}$. For analysis of phase assemblages and morphology, the fresh 
Juan M. Pérez, Jesús Ma. Rincón, Maximina Romero Effect of moulding pressure on microstructure and technological properties of porcelain stoneware. Ceramics International Volume 38, Issue 1, January 2012, Pages 317-32; doi:10.1016/j.ceramint.2011.07.009

fractures surfaces were etched for $4 \mathrm{~min}$ in $15 \% \mathrm{HF}$ solution, washed ultrasonically with distilled water and ethylic alcohol, dried and subsequently $\mathrm{Au}-\mathrm{Pd}$ coated in a Balzers SCD 050 sputter. Secondary electron images (SEI) were used for microstructure examination.

\section{Results and discussion}

\subsection{Green tiles}

Fig. 1 shows the variation of density values as a function of moulding pressure (MP). As expected, there are no important changes in absolute density as MP increases, and all the green tiles proportionate density values close to $2.50 \mathrm{~g} / \mathrm{cm}^{3}$, which is in the range of the theoretical value $\left(2.52 \mathrm{~g} / \mathrm{cm}^{3}\right)$ corresponding to the proportion of different raw materials in the porcelain stoneware body. This result is due to helium pycnometer can measure absolute density with high accuracy because helium gas penetrates surface cavities as small as about 1 A. However, the bulk density of green samples is higher as MP increases with values varying from 1.8 to $2.0 \mathrm{~g} / \mathrm{cm}^{3}$, corresponding to 10 and $40 \mathrm{MPa}$, respectively. This variation is due to the different compaction of the green tiles. As the MP increases, the size of internal pores decreases, and the packing degree increases, which results in higher values of bulk density. The variation showed in bulk density is not linear. There is a threshold pressure between 20 and $30 \mathrm{MPa}$, which shows the biggest jump in bulk density $(6 \%)$.

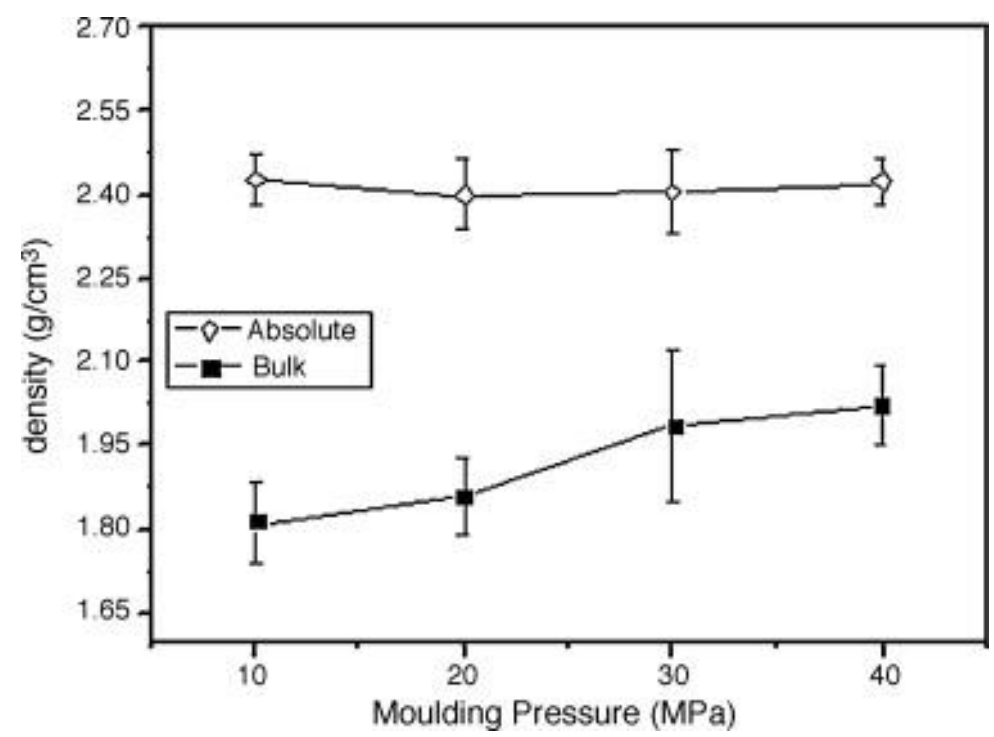

Fig. 1. Absolute and bulk densities of green tiles at different moulding pressures (lines are drawn to guide eyes in this figure, Fig. 2, Fig. 3, Fig. 4 and Fig. 12). 
Juan M. Pérez, Jesús Ma. Rincón, Maximina Romero Effect of moulding pressure on microstructure and technological properties of porcelain stoneware. Ceramics International Volume 38, Issue 1, January 2012, Pages 317-32; doi:10.1016/j.ceramint.2011.07.009

Fig. 2 depicts the variation of bending strength of the green tiles as a function of MP. In all cases, the rupture modulus (MOR) is higher than $0.1 \mathrm{MPa}$, which is the minimum value that allows working with green bodies to extract the tiles from the die and convey them along the manufacturing line. The effect of MP can be checked by the difference in $\sigma_{\mathrm{f}}$ values corresponding to the lower and the higher pressures, 10 and $40 \mathrm{MPa}$, respectively. These values vary from 3 to $4.5 \mathrm{MPa}$, which corresponds to a $50 \%$ increase in bending strength. However, this variation is not lineal, but it depicts a s-shape curve. Thus, the higher increase in $\sigma_{\mathrm{f}}$ can be appreciated between tiles pressed at 20 and $30 \mathrm{MPa}(27 \%)$ but the variation is slightly lower between 10 and $20 \mathrm{MPa}(15 \%)$ and significantly inferior between 30 and $40 \mathrm{MPa}(3 \%)$. This behaviour also indicates the presence of a threshold value already mentioned. Beyond this value, the increment of MP causes a slight variation in $\sigma_{\mathrm{f}}$. This agrees with Fig. 1 , as MP increases, compaction of green tiles is higher and the bending strength improves.

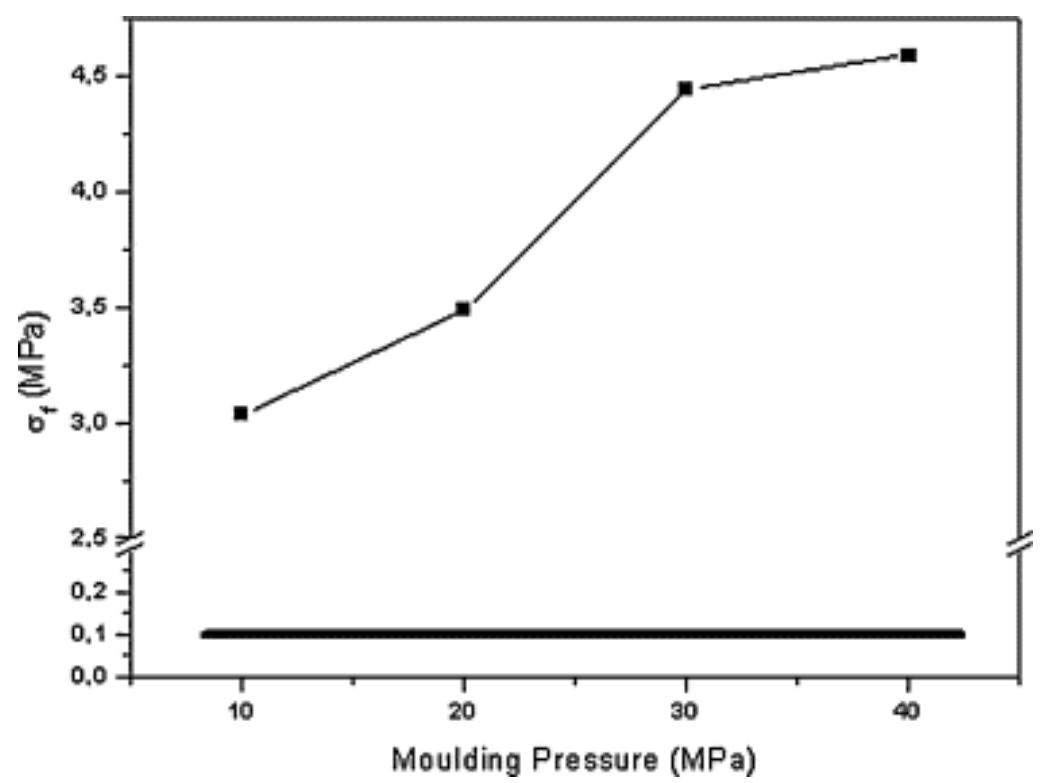

Fig. 2. Bending strength of green tiles. Solid line $(0.1 \mathrm{MPa})$ is the minimum value required to green tiles.

\subsection{Fired bodies}

Fig. 3 shows the variation of LS and WA after fast-firing process of bodies moulded at different pressure. Low pressures (10 and $20 \mathrm{MPa}$ ) have an important effect on LS. The porosity of green compacts pressed at low pressure is relatively high, as indicated by the difference in the values of bulk and absolute density (Fig. 1). In liquid phase sintering, the wetting liquid acts on 
Juan M. Pérez, Jesús Ma. Rincón, Maximina Romero Effect of moulding pressure on microstructure and technological properties of porcelain stoneware. Ceramics International Volume 38, Issue 1, January 2012, Pages 317-32; doi:10.1016/j.ceramint.2011.07.009

the solids particle to eliminate porosity and reduce interfacial energy, since higher-energy solidvapor interfaces are gradually replaced by lower-energy solid-solid interfaces with a total decrease in free energy occurring on sintering. Consequently, shrinkage of the fired body decreases as the green density of the compact increases.

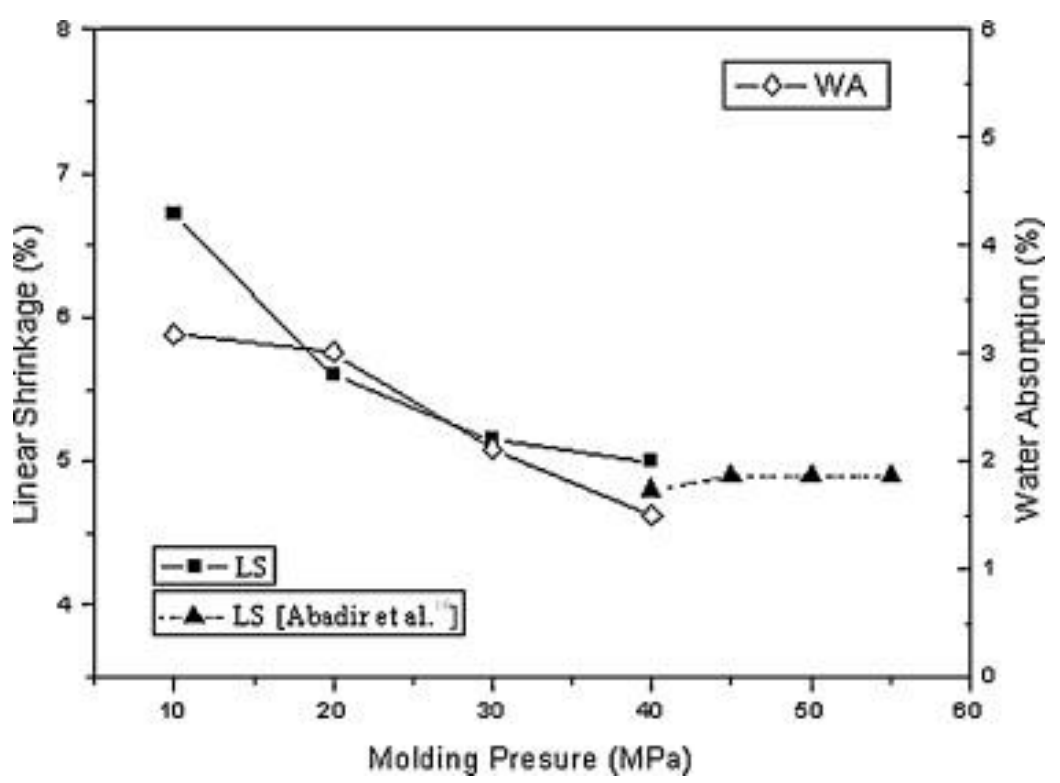

Fig. 3. Linear shrinkage (LS) and water absorption (WA) of fired bodies. Triangles data are from Abadir et al. [10].

Evidently, the larger the volume of voids in the green body, the greater the degree of sintering after firing and therefore, the greatest variations in shrinkage take place between the samples pressed at $10 \mathrm{MPa}$ and $20 \mathrm{MPa}$, whereas this difference is almost negligible between bodies pressed at $30 \mathrm{MPa}$ and $40 \mathrm{MPa}$.

LS values have same tendency as reported by Abadir et al. [10]. They concluded that increasing the MP above $45 \mathrm{MPa}$ did not enhance the sintering degree of fired tiles (Fig. 3).

Fig. 3 also shows that water absorption decreases as MP increases, as a result of the higher densification. However, WA of compacts pressed at $10 \mathrm{MPa}$ and $20 \mathrm{MPa}$ are similar. As water absorption is directly related to open porosity, this result indicates that shrinkage decrease takes place between bodies pressed at $10 \mathrm{MPa}$ and $20 \mathrm{MPa}$ must be due to a decrease in closed porosity. Therefore, as the MP increases the capability of absorption of the tiles decreases. The water absorption values are lower than the value required in the UNI EN ISO 13006 for this type of tiles $(0.5 \%)$, which is likely due to the differences between industrial and laboratory 
Juan M. Pérez, Jesús Ma. Rincón, Maximina Romero Effect of moulding pressure on microstructure and technological properties of porcelain stoneware. Ceramics International Volume 38, Issue 1, January 2012, Pages 317-32; doi:10.1016/j.ceramint.2011.07.009

facilities. The compaction process used in manufacturing porcelain stoneware tile typically consist of a double-pressing technology, which involves a first pressing step at very low pressure values (30-60 bar) to produce a semi-compact body with a minimum mechanical strength, in which layers of powder decoration are applied. After the pre-compacted body has gone through the decoration processes, it is placed inside a second die for definitive pressing at the traditional porcelain stoneware tile shaping pressure (400 bar) [3] and [9]. Moreover, in the industrial process the raw material batch is spray-dried before pressing. Both steps (spraydrying and double-pressing) increase the contact between particles in the green body and favour the porosity elimination during firing. Nevertheless, those facilities are not usually available in minor-scale investigation in research laboratories, and therefore, it is necessary longer treatment (temperature and time) to achieve a water absorption $<0.5 \%$. As an example, Abadir et al. [10] reach water absorption of 5\% after firing at same conditions of present paper. To reduce water absorption down to $0.5 \%$ in laboratory investigations, it is necessary to increase firing temperature or time, which will also modify the crystalline phases distribution. The porcelain stoneware body under investigation is formulated to study the effect of moulding pressure on mullite morphology (shape and size), as well as on physical and technological properties of the end product. Thus, in present paper, it has been chosen the maintenance a soaking time similar to that used in the industrial process (15-20 $\mathrm{min})$. The water absorption values obtained in this investigation is high but it is due to the laboratory conditions of material processing and that it will not affect to mullite formation.

Fig. 4 depicts the variation of open, close and total porosity $\left(\varepsilon_{0}, \varepsilon_{\mathrm{c}}\right.$ and $\varepsilon_{\mathrm{T}}$, respectively). Again, the values presented have same tendency as those previously reported by Abadir et al. [10]. Water absorption is directly associated to open porosity and thus, both depict the same trend and the open porosity decreases as MP increases up to $40 \mathrm{MPa}$, but between 10 and $20 \mathrm{MPa}$ there is little variation, in agreement with previous WA results ( Fig. 3). However, close porosity experiments a significant decrease as pressure increases up to $30 \mathrm{MPa}$, but it increases at higher pressure likely due to bloating that occurs because of the difficulty to release gases entrapped in bodies pressed at high pressures, as in the first stage of sintering a high green compactness locks the microstructure and inhibits the rearrangement of particles [20]. Consequently, the total porosity of fired tiles decreases from 10 to $30 \mathrm{MPa}$, reaching a minimum value that remains constant at higher pressures, but the common MP (40 MPa) presents very close properties to $30 \mathrm{MPa}$. 
Juan M. Pérez, Jesús Ma. Rincón, Maximina Romero Effect of moulding pressure on microstructure and technological properties of porcelain stoneware. Ceramics International Volume 38, Issue 1, January 2012, Pages 317-32; doi:10.1016/j.ceramint.2011.07.009

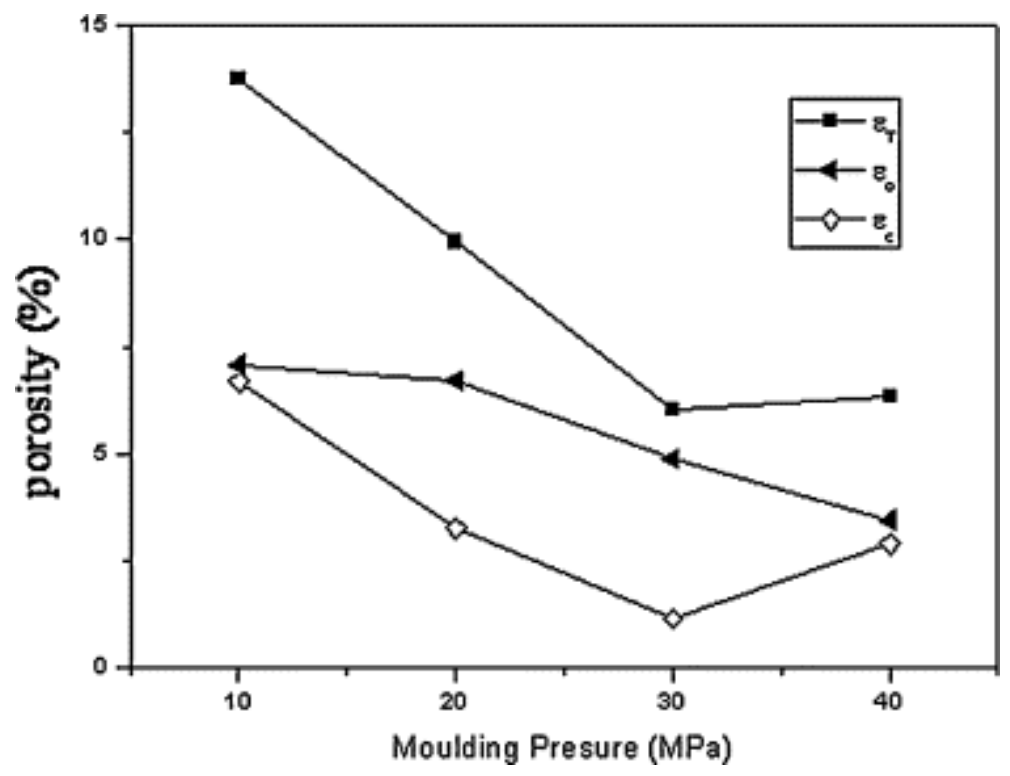

Fig. 4. Variation of open $(\varepsilon o)$, close $(\varepsilon c)$ and total $(\varepsilon T)$ porosity of fast-fired stoneware tiles.

The above results indicate that as far as total porosity and linear shrinkage is concerned, the differences in the properties obtained with pressures of $30 \mathrm{MPa}$ and $40 \mathrm{MPa}$ are negligible.

Fig. 5 shows the microstructure of fired porcelain stoneware moulded at different pressures. In the SEM micrographs it can be seen the existence of both open and close porosity after firing. As usual, open porosity consists of fine and interconnected pores with irregular shape; whereas, closed porosity is due to larger, isolated and spherical pores. Fig. 5 points out that in general open porosity decreases as MP increases, although the porosity degree showed by fired tiles pressed at $10 \mathrm{MPa}$ and $20 \mathrm{MPa}$ is comparable. Higher MP lead to highly compacted green bodies with lower volume of voids and, therefore, the elimination of open pores by the liquid phase formed on firing is favoured. Close porosity also decreases in both number and size as MP increases, with a maximum pore size varying from $64 \mu \mathrm{m}$ at $10 \mathrm{MPa}$ to $51 \mu \mathrm{m}$ at $40 \mathrm{MPa}$. However, in this case the minimum pore size is reached in bodies pressed at $20 \mathrm{MPa}(43 \mu \mathrm{m})$ and the minimum number of pores is observed in the SEM micrograph on tile pressed at $30 \mathrm{MPa}$, with an increase in both number and size of pores in tiles pressed at $40 \mathrm{MPa}$. As mentioned above, this behaviour may be due to the impediment to gases release by the high compactness of tiles pressed at higher pressures. SEM observations show the same trend in open and close porosity that showed by directly porosity measurement (Fig. 4). 
Juan M. Pérez, Jesús Ma. Rincón, Maximina Romero Effect of moulding pressure on microstructure and technological properties of porcelain stoneware. Ceramics International Volume 38, Issue 1, January 2012, Pages 317-32; doi:10.1016/j.ceramint.2011.07.009

a

$\mathrm{b}$
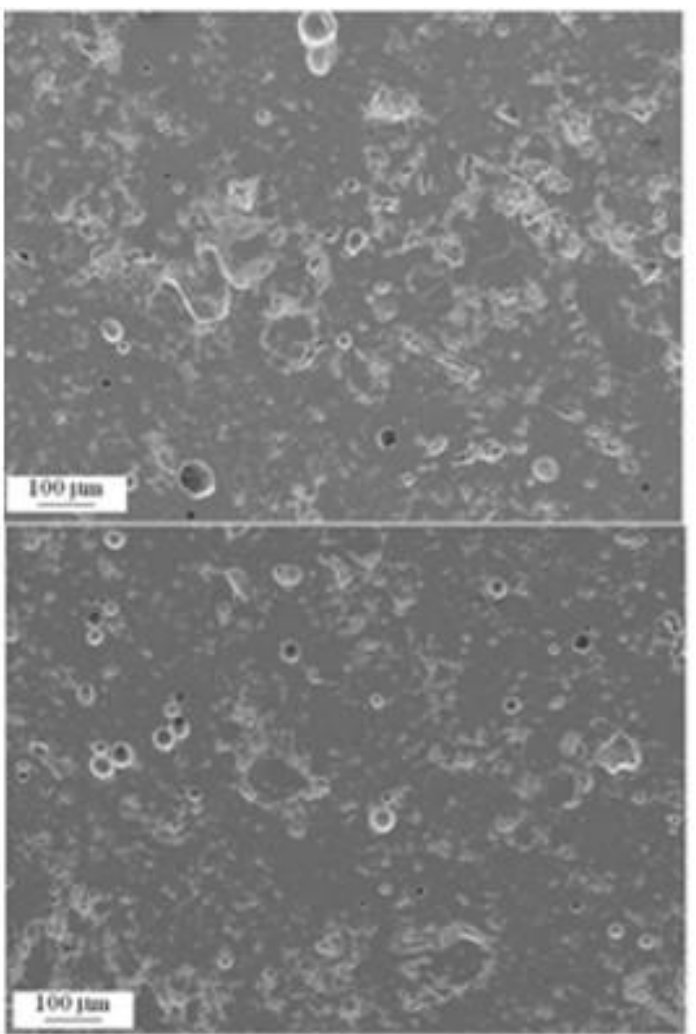

$\mathrm{c}$

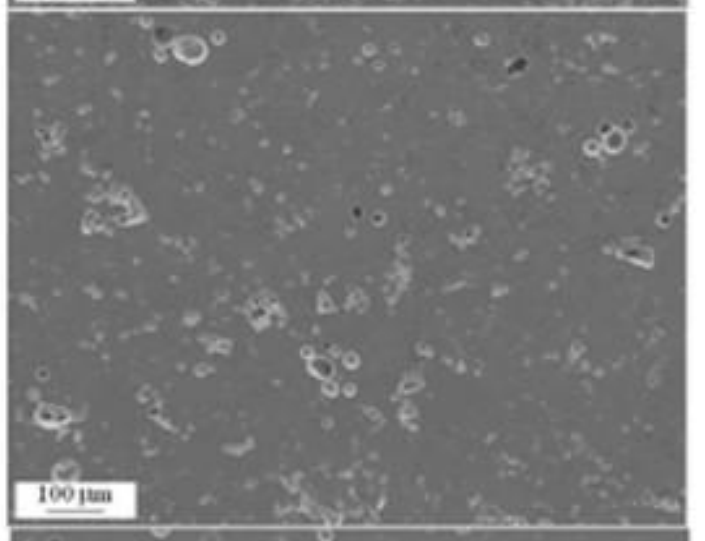

d
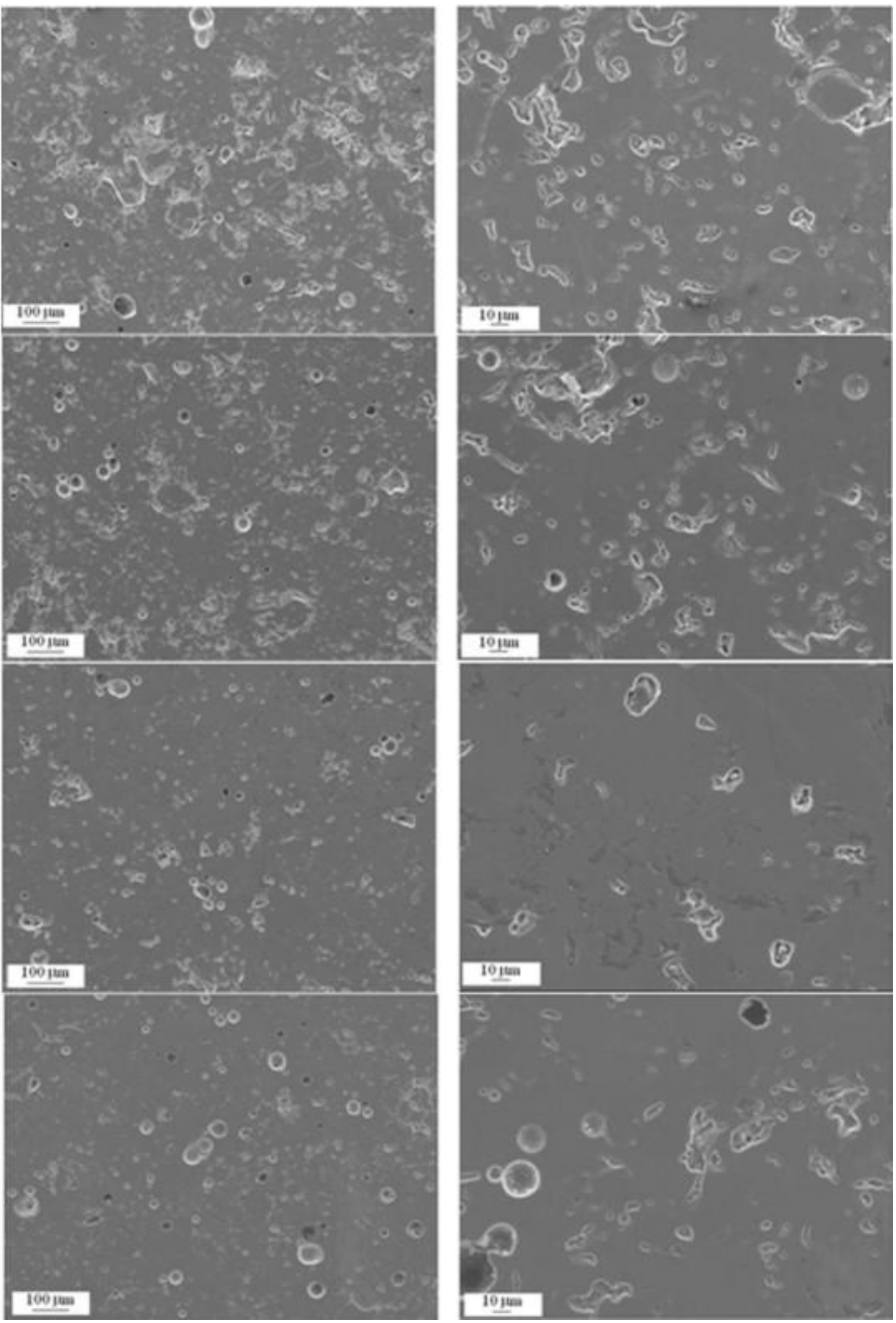

Fig. 5. SEM micrographs on polished surfaces of the porcelain stoneware at different moulding pressures: (a) $10 \mathrm{MPa}$, (b) $20 \mathrm{MPa}$, (c) $30 \mathrm{MPa}$ and (d) $40 \mathrm{MPa}$. 
Juan M. Pérez, Jesús Ma. Rincón, Maximina Romero Effect of moulding pressure on microstructure and technological properties of porcelain stoneware. Ceramics International Volume 38, Issue 1, January 2012, Pages 317-32; doi:10.1016/j.ceramint.2011.07.009

Fig. 6 shows the effect of MP on fired bending strength. As it can be seen, low MP lead to materials with less strength in bending, with $\sigma_{\mathrm{f}}$ ranging from 27 to $35 \mathrm{MPa}$, which corresponds to an improvement in flexural by almost $30 \%$. In green tiles, the bigger jump of the values was between 20 and $30 \mathrm{MPa}$, now this increase is from 10 to $20 \mathrm{MPa}$. MP has a significant influence on green bending strength but the variation observed in fired tiles is less noticeable. The main factor affecting bending strength of green bodies is porosity, because as less pores exist, there is less space to contribute the fracture, since it is known that the relative fracture energy is influenced by pore volume fraction [21], which is the only varying parameter in green bodies moulded at different pressure. Nevertheless, although open porosity has an effect on bending strength in fired tiles [16], there are other factors affecting, such as mullite formation and quartz particles [3], [4], [5], [15] and [22].

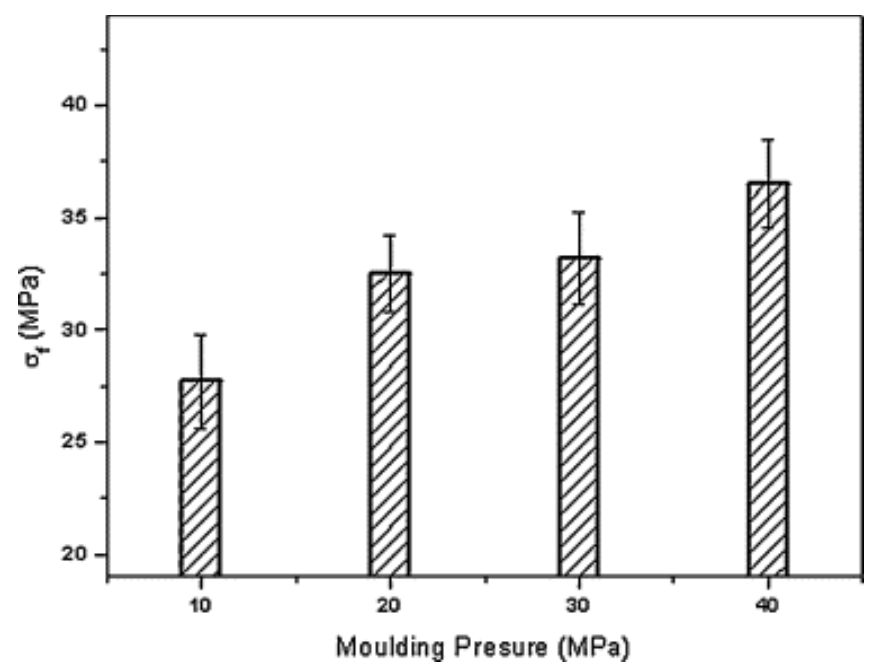

Fig. 6. Bending strength of fired tiles.

Fig. 7 shows the X-ray diffractograms of fired porcelain body. In all the cases, showed in this study, that fired porcelain stoneware is composed by mullite and quartz. It can be observed that the amount of crystalline phase is independent of MP since the intensity of X-ray peaks shows negligible variations as can be seen in the box at the top of Fig. 7. These results show that the amount of mullite formed on firing only depends on clay percentage, temperature and firing time, not by the initial MP. However, as above mentioned MP has an important effect on bending strength of fired tiles. These results indicate that the main factor affecting to bending strength increment must be mullite morphology, which likely is influenced by the MP. 


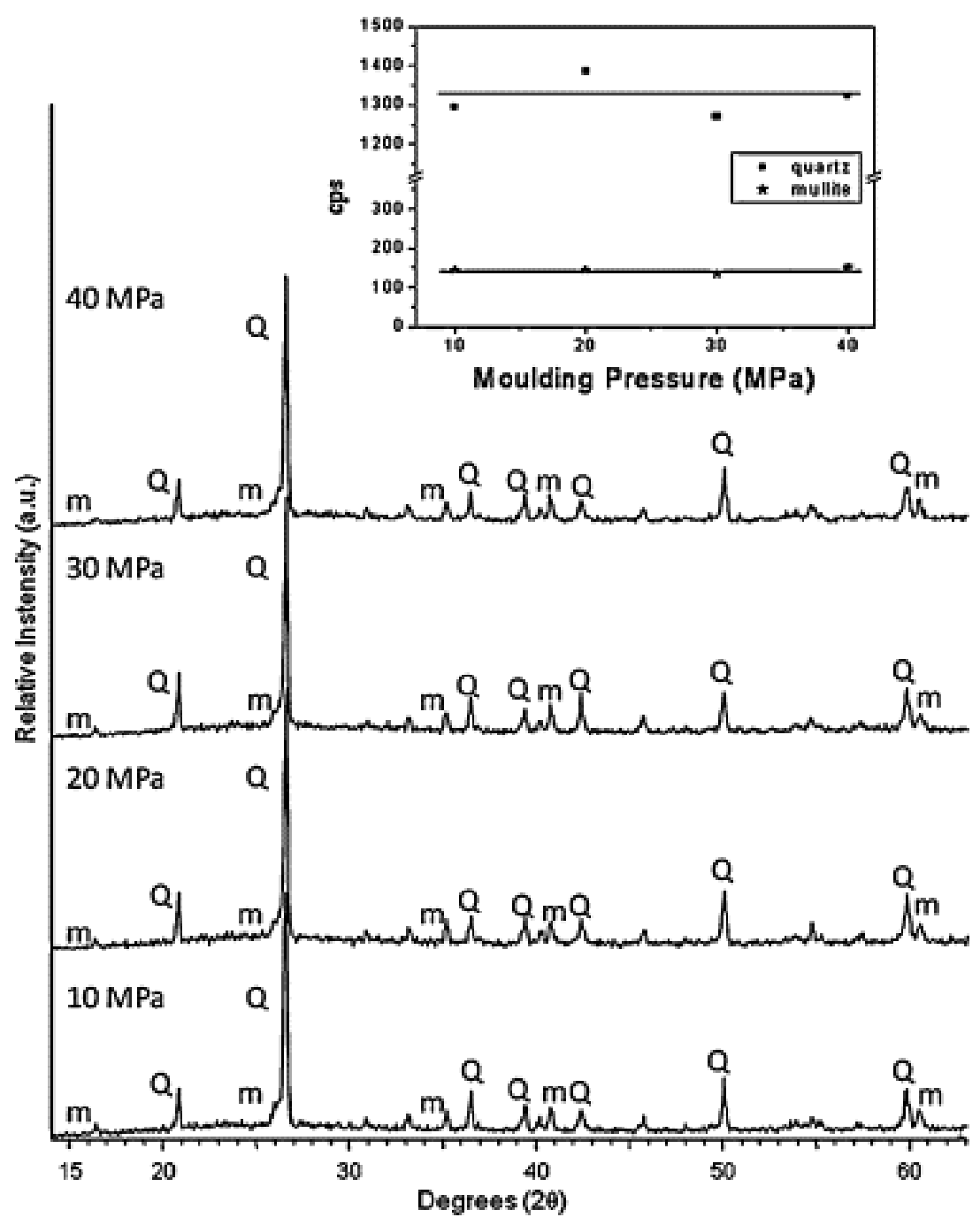

Fig. 7. X-ray diffractograms of the fired porcelain body at different moulding pressures. Top box represents the variation in the intensity of quartz $\left(2 \theta=26.5^{\circ}\right)$ and mullite $\left(2 \theta=60.6^{\circ}\right)$ peaks.

Fig. 8 shows the micrographs of porcelain stoneware samples moulded at $10 \mathrm{MPa}$ and fired at $1280{ }^{\circ} \mathrm{C}$. After firing, all samples show a typical grain and bond porcelain microstructure with coarse quartz particles held together by a finer matrix consisting of mullite crystals and a glassy phase [6]. Mullite crystals are observed as fine cuboidal crystals, which correspond to primary mullite developed from pure clay agglomerate relicts, and also as secondary mullite composed by elongated needle-shaped crystals formed in those regions in which feldspar particles were well mixed with kaolinitic clay or where feldspar has gone through clay agglomerates [23]. 


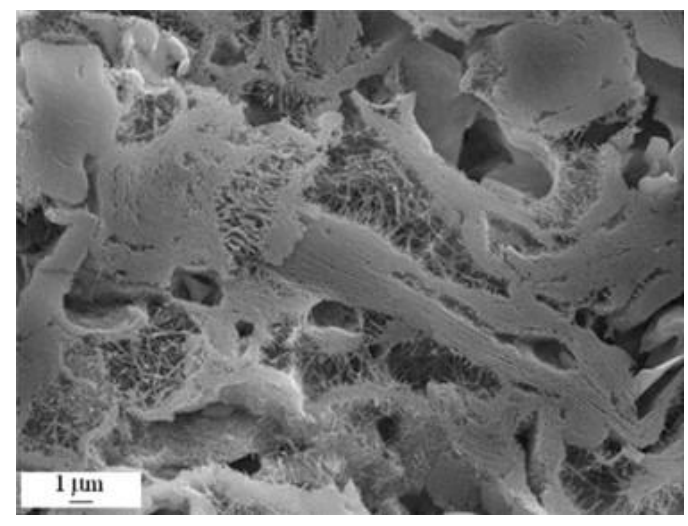

Fig. 8. SEM micrograph of porcelain stoneware pressed at $10 \mathrm{MPa}$.

Fig. 9 shows in more detail the morphology of secondary mullite developed after firing. In porcelain stoneware sample pressed at the lowest value (10 MPa), most of needle-like mullite crystals are $\sim 1.1-1.7 \mu \mathrm{m}$ long and $\sim 0.1 \mu \mathrm{m}$ wide, which corresponds to a mean aspect ratio of 14:1. By considering the notation proposed by Iqbal and Lee [1], these crystals could be considered as secondary Type II mullite. At higher MP mullite crystals show similar width to those developed at lower pressure but greater length, from 1.8 to $3.1 \mu \mathrm{m}$ at $20 \mathrm{MPa}$ up to 5.5 to $6.6 \mu \mathrm{m}$ in samples pressed at $40 \mathrm{MPa}$. Therefore, their aspect ratio increases with MP up to means values of 33:1, 43:1 and 55:1 in samples pressed at 20, 30 and $40 \mathrm{MPa}$, respectively, and thus, these crystals could be considered as secondary Type III mullite. In all SEM/SE images is observed as secondary Type III mullite fibres join together and give rise to clusters or packs of needles. A similar morphology has been recently described in a study on mullite development on firing in porcelain stoneware bodies [6].

In porcelain stoneware, the development of Types II and III secondary mullite on firing is assisted by the liquid phase formed on firing as result of the melting of feldspar component and partial dissolution of quartz particles in the new formed melt. Martín-Márquez et al. [6]pointed out that primary mullite crystals formed at the external surface of pure clay agglomerates, could grow out and transform into secondary mullite crystals if they are near a lower viscosity matrix. As described above, MP has minor effect on the percentage of amorphous and crystalline phases after firing (Fig. 7). Hence, with independence of MP, mullite crystals developed during firing should be surrounded by a similar amount of liquid phase, which must also have comparable viscosity since all samples have the same batch composition and firing schedule. Therefore, the differences observed in the aspect ratio of mullite needles in samples moulded at different 
Juan M. Pérez, Jesús Ma. Rincón, Maximina Romero Effect of moulding pressure on microstructure and technological properties of porcelain stoneware. Ceramics International Volume 38, Issue 1, January 2012, Pages 317-32; doi:10.1016/j.ceramint.2011.07.009

pressure must be related to the arrangement of mullite crystals and liquid phase during firing, which is to the contact degree between both phases.
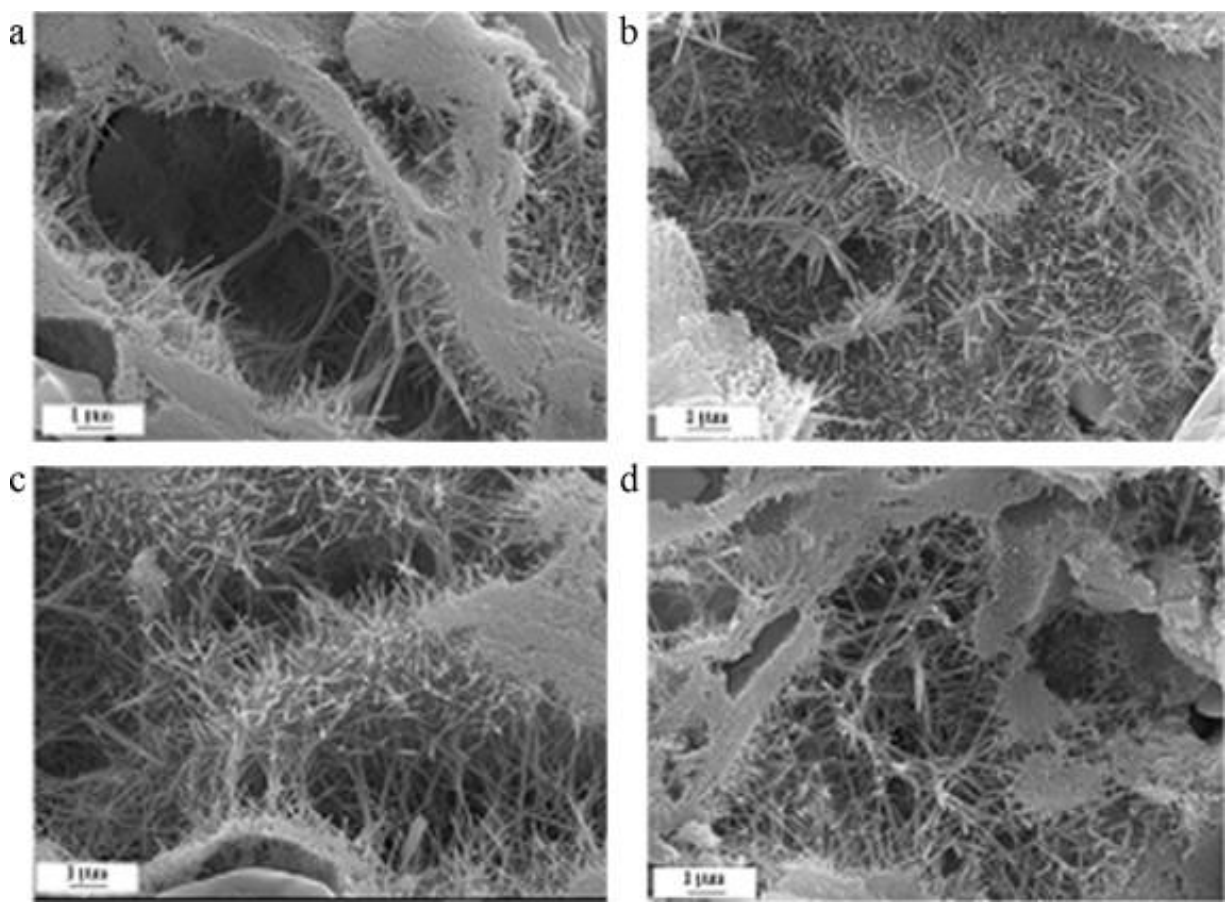

Fig. 9. SEM micrographs of fresh fractured fired tiles at different moulding pressures: (a) $10 \mathrm{MPa}$ (b) $20 \mathrm{MPa}$, (c) $30 \mathrm{MPa}$ and (d) $40 \mathrm{MPa}$.

High MP (HP) samples leads to a very compacted green body with pores smaller than those in lower pressure (LP) samples. If we consider that the volume of liquid phase formed on firing is approximately equal to the volume of pores in HP sample, the liquid phase practically fills the pores and the surface of all particles are in contact with liquid phase. However, in samples pressed at lower pressures, which have larger pore volume, the liquid phase does not fill the whole pore volume part of the pores, leaving part of the particle surface without contact with the formed liquid phase. In HP sample, mullite crystals developed at the pore interface find a lower viscosity melt, which favours the growth of needle-like crystals throughout their longitudinal axis, and consequently their aspect ratio increases up to values $>30: 1$, which corresponds to Type III secondary mullite. Nevertheless, mullite crystals developed at the pore interface in LP sample find a lower volume of low viscosity of liquid phase, and although crystals grow through a diffusion mechanism, they reach lower length, leading to an aspect ratio <20:1, which corresponds to Type II secondary mullite. To help the understood of the moulding 
Juan M. Pérez, Jesús Ma. Rincón, Maximina Romero Effect of moulding pressure on microstructure and technological properties of porcelain stoneware. Ceramics International Volume 38, Issue 1, January 2012, Pages 317-32; doi:10.1016/j.ceramint.2011.07.009

pressure effects, in Fig. 10 has been depicted a schema for liquid phase formation and secondary mullite crystals growth during firing in samples moulded at LP and high HP. Moreover, in LP sample mullite crystals might form in an interfacial area adjacent to a very low volume, or no liquid phase. In this case, the growth throughout their longitudinal axis is impeded and mullite crystals grow on the surface of clay particle, resulting in a highly oriented and textured microstructure, as it is showed in Fig. 11.

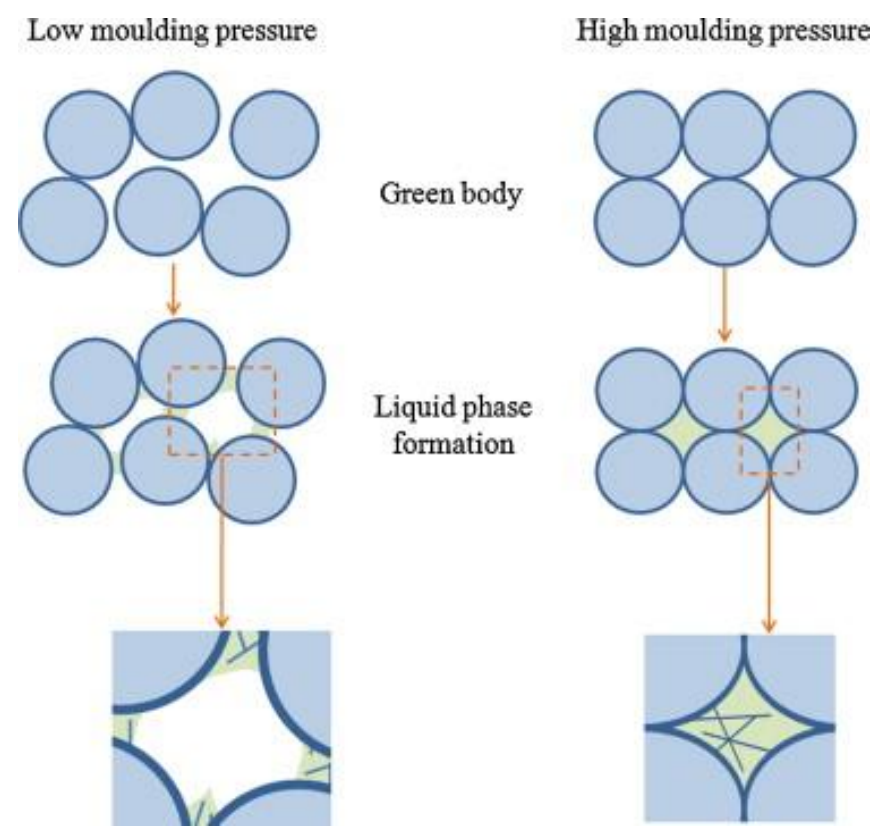

Fig. 10. Schematic drawing for liquid phase formation and secondary mullite crystals growth at low and high moulding pressure.

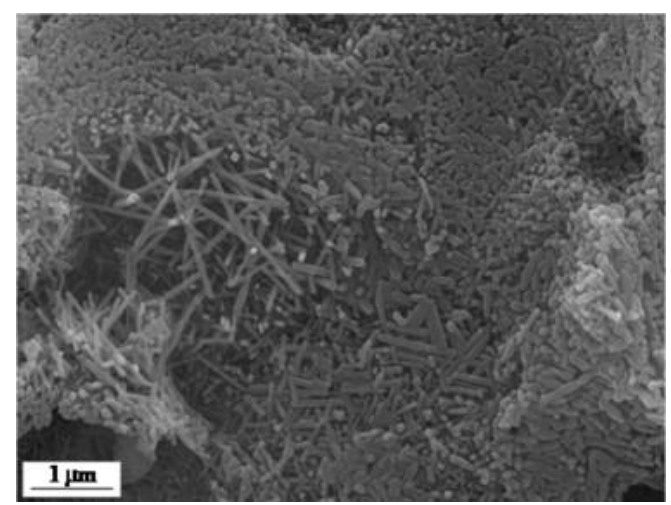

Fig. 11. SEM micrograph of porcelain stoneware pressed at $30 \mathrm{MPa}$. 
In a recent work, Martín-Márquez el al. [22] have shown that bending strength in porcelain stoneware is directly associated to the aspect ratio shown by secondary mullite needles. As seen in Fig. 6, bending strength increases with MP, which also gives rise to higher aspect ratio of mullite needles. Fig. 12 depicts the variation of bending strength as a function of the aspect ratio showed by secondary mullite needles developed in samples moulded at different pressures, compared with the results obtained by Martín-Márquez et al. [22]. Both curves fit together and yet again, it can be observed that both factors are directly associated and bending strength improves when the aspect ratio increases from 14:1 in samples pressured at $10 \mathrm{MPa}$ to 55:1 in those at $40 \mathrm{MPa}$.

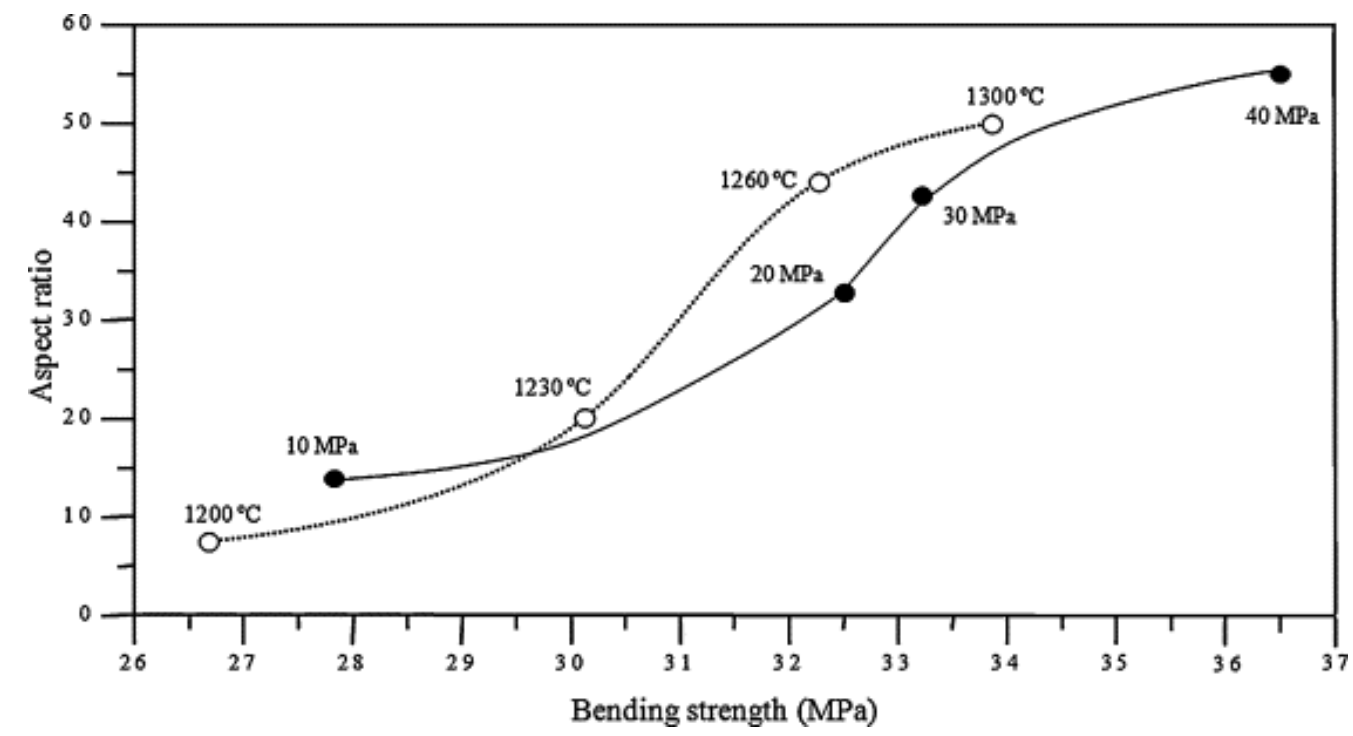

Fig. 12. Variation of bending strength as a function of the aspect ratio shown by secondary mullite needles at different moulding pressures. Empty circles are values from Martín-Márquez et al. [22].

\section{Conclusions}

A study of moulding pressure influence on microstructure and properties of green and fired stoneware porcelain tiles has been performed. A mixture of kaolinitic clay (50\%), feldspar (40\%) and quartz (10\%) was selected. Four moulding pressures (10, 20, 30 and $40 \mathrm{MPa}$ ) have been employed to obtain the green tiles, which have been undergone to a fast firing process. As the presented results show, it can be concluded that:

a. For all pressures assayed, the module of rupture of green tiles is higher than $0.1 \mathrm{MPa}$ which is the minimum value that allows workability. Besides, green 
Juan M. Pérez, Jesús Ma. Rincón, Maximina Romero Effect of moulding pressure on microstructure and technological properties of porcelain stoneware. Ceramics International Volume 38, Issue 1, January 2012, Pages 317-32; doi:10.1016/j.ceramint.2011.07.009

tiles pressed at $30 \mathrm{MPa}$ show similar bending strength than $40 \mathrm{MPa}$. Bigger differences are found at low moulding pressures.

b. The greatest variations in shrinkage take place between the samples pressed at 10 and $20 \mathrm{MPa}$, whereas this difference is almost negligible between bodies pressed at 30 and $40 \mathrm{MPa}$.

c. As the moulding pressure increases the capability of absorption of the tiles decreases.

d. Both closed and total porosity decreases as moulding pressures increases up to $30 \mathrm{MPa}$.

e. Bending strength of tiles pressed at 20,30 and $40 \mathrm{MPa}$ are very close, the lowest value is presented at $10 \mathrm{MPa}$.

f. The amount of crystalline phases is independent of moulding pressure.

g. The morphology of secondary mullite is affected by initial moulding pressure. It varies from Type II at low pressure to Type III at higher pressures. The secondary Type III mullite fibres join together and give rise to cluster or pack of needles.

h. Bending strength improves when the aspect ratio increases from 14:1 in samples pressured at $10 \mathrm{MPa}$ to $55: 1$ in those at $40 \mathrm{MPa}$.

\section{Acknowledgements}

The authors would like to acknowledge Miss P. Díaz (CSIC) and IRICA (University of Castilla-La Mancha, Spain) for the technical support of the experimental work. J.M. Pérez acknowledges to CSIC for the financial support by contract JAEDoc_08_00362.

\section{References}

[1] Y. Iqbal, W.E. Lee, Fired porcelain microstructure revisited, J. Am. Ceram. Soc., 82 (1999), pp. 3584-3590

[2] M. Romero, J. Martín-Márquez, J.Ma. Rincón, Kinetic of mullite formation from a porcelain stoneware body for tiles production, J. Eur. Ceram. Soc., 26 (2006), pp. 1647-1652

[3] C. Leonelli, F. Bondioli, P. Veronesi, M. Romagnoli, T. Manfredini, G.C. Pellacani, V. Cannillo, Enhancing the mechanical properties of porcelain stoneware tiles: a microstructural approach, J. Eur. Ceram. Soc., 21 (2001), pp. 785-793 
Juan M. Pérez, Jesús Ma. Rincón, Maximina Romero Effect of moulding pressure on microstructure and technological properties of porcelain stoneware. Ceramics International Volume 38, Issue 1, January 2012, Pages 317-32; doi:10.1016/j.ceramint.2011.07.009

[4] E. Sánchez, M.J. Orts, J. García-Tena, V. Cantavella, Porcelain tile composition effect on phase formation and end products, Am. Ceram. Soc. Bull., 80 (2001), pp. 43-49

[5] M. Dondi, G. Guarini, C. Melandri, M. Raimondo, P.M.T. Cavalante, C. Zanelli, Resistance to deep abrasion of porcelain stoneware tiles, Ind. Ceram., 25 (2005), pp. 71-78

[6] J. Martín-Márquez, J.Ma. Rincón, M. Romero, Mullite development on firing in porcelain stoneware bodies, J. Eur. Ceram. Soc., 30 (2010), pp. 1599-1607

[7] S.L. Correia, A.P.N. Oliveira, D. Hotza, A.M. Segadães, Properties of triaxial porcelain bodies: interpretation of statistical modelling, J. Am. Ceram. Soc., 89 (2006), pp. 3356-3365

[8] J.M. Amigó, J.V. Clausell, V. Esteve, J.M. Delgado, M.M. Reventós, L.E. Ochando, X-ray powder diffraction phase analysis and thermomechanical properties of silica and alumina porcelains, J. Am. Ceram. Soc., 24 (2004), pp. 75-81

[9] A. Bresciani, G.P. Graziani, C. Ricci, New grès porcellanato tile manufacturing technology: prepressing dry decoration, and green cutting, Interceram, 51 (2002), pp. 380-386

[10] M.F. Abadir, E.H. Sallam, I.M. Bakr, Preparation of porcelain tiles from Egyptian raw materials, Ceram. Int., 28 (2002), pp. 303-310

[11] J. Martín-Márquez, J.Ma. Rincón, M. Romero, Effect of firing temperature on sintering of porcelain stoneware tiles, Ceram. Int., 34 (2008), pp. 1867-1873

[12] M. Dondi, G. Ercolani, C. Melandri, C. Mingazzini, M. Marsigli, The chemical composition of porcelain stoneware tiles and its influence on microstructural and mechanical properties, Interceram, 48 (1999), pp. 75-83

[13] T. Manfredini, G.C. Pellacani, M. Romagnoli, Porcelainized stoneware tile, Am. Ceram. Soc. Bull., 74 (1995), pp. 76-79

[14] L. Barbieri, L. Bonfatti, A.M. Ferrari, C. Leonelli, T. Manfredini, D. Settembre, Relationship between microstructure and mechanical properties in fully vitrified stoneware, P. Vincenzini (Ed.), Ceramics: Charting the Future, vol. 3ATechna Srl, Modena (1995), pp. 99-105

[15] S.R. Bragança, C.P. Bergmann, A view of whitewares mechanical strength and microstructure, Ceram. Int., 29 (2003), pp. 801-806

[16] T.K. Mukhopadhyay, S. Ghatak, H.S. Maiti, Effect of pyrophyllite on the mullitization in triaxial porcelain system, Ceram. Int., 35 (2009), pp. 1493-1500

[17] H.J. Alves, F.G. Melchiades, A.O. Boschi, Effect of spray-dried powder granulometry on the porous microstructure of polished porcelain tile, J. Eur. Ceram. Soc., 30 (2010), pp. 1259-1265 
Juan M. Pérez, Jesús Ma. Rincón, Maximina Romero Effect of moulding pressure on microstructure and technological properties of porcelain stoneware. Ceramics International Volume 38, Issue 1, January 2012, Pages 317-32; doi:10.1016/j.ceramint.2011.07.009

[18] A. De Noni, D. Hotza, V. Cantavella, E. Sánchez, Influence of composition on mechanical behaviour of porcelain tile. Part I. Microstructural characterization and development phases after firing, Mater. Sci. Eng. A, 527 (2010), pp. 1730-1735

[19] D. Njoya, M. Hajjaji, A. Baçaoui, D. Njopwpuo, Microstructural characterization and influence of manufacturing parameters on technological properties of vitreous ceramic materials, Mater. Charact., 61 (2010), pp. 289-295

[20] J. Ranogajec, M. Djuric, M. Radeka, P. Jovanic, Influence of particle size and furnace atmosphere on the sintering of powder for tiles production, Ceram. Silik., 44 (2000), pp. 71-77

[21] L.J. Vandeperre, J. Wang, W.J. Clegg, Effects of porosity on the measured fracture energy of brittle materials, Philos. Mag., 84 (2004), pp. 3689-3704

[22] J. Martín-Márquez, J.Ma. Rincón, M. Romero, Effect of microstructure on mechanical properties of porcelain stoneware, J. Eur. Ceram. Soc., 30 (2010), pp. 3063-3069

[23] Y. Iqbal, E.J. Lee, Microstructural evolution in triaxial porcelain, J. Am. Ceram. Soc., 83 (2000), pp. $3121-3127$ 